\author{
UNIVERSIDADE DE SÃO PAULO ${ }^{1}$ \\ CENTRO UNIVERSITÁRIO SÃO CAMILO²
}

\title{
DESENVOLVIMENTO DE IMUNOLIPOSSOMOS PARA O TRATAMENTO DE TUMORES
}

CATEGORIA CLÍNICO

Giovana Fioravante Romualdo ${ }^{1,2}$; Giovana da Silva Leandro ${ }^{1}$; Carlos Frederico Martins Menck ${ }^{1}$; Gerhard Wunderlinch ${ }^{1}$; Wesley Luzetti Fotoran ${ }^{1}$

gi romualdo@hotmail.com

(11) 953426513 
Jardim Santa Mena- Guarulhos, SP.

\title{
DESENVOLVIMENTO DE IMUNOLIPOSSOMOS PARA O TRATAMENTO DE TUMORES
}

\author{
CATEGORIA CLÍNICO
}

Descritores: nanopartículas; imunolipossomos; tumores; nanomedicina;

Giovana Fioravante Romualdo ${ }^{1,2}$; Giovana da Silva Leandro ${ }^{1}$; Carlos Frederico 


\title{
Martins Menck ${ }^{1}$; Gerhard Wunderlinch ${ }^{1}$; Wesley Luzetti Fotoran ${ }^{1}$ \\ DESENVOLVIMENTO DE IMUNOLIPOSSOMOS PARA O TRATAMENTO DE TUMORES
}

\author{
UNIVERSIDADE DE SÃO PAULO ${ }^{1}$ \\ CENTRO UNIVERSITÁRIO SÃO CAMILO ${ }^{2}$
}

Giovana Fioravante Romualdo ${ }^{1,2}$; Giovana da Silva Leandro ${ }^{1}$; Carlos Frederico Martins Menck ${ }^{1}$; Gerhard Wunderlinch ${ }^{1}$; Wesley Luzetti Fotoran ${ }^{1}$

\section{Resumo}

Introdução: O uso de fármacos com diferentes finalidades em órgãos/tecidos específicos sofre dois grandes problemas, a ineficácia das quantidades necessárias para desencadear respostas farmacológicas, bem como possíveis efeitos colaterais causados pelo fármaco, além do mais, existem barreiras fisiológicas tais como a hematoencefálica e ligantes específicos que permitem o acesso de agentes terapêuticos a tecidos específicos. Dentre as diversas propostas biotecnológicas para resolução desses problemas estão o uso de lipossomos para reduzir a toxicidade e biodisponibilizar fármacos em quantidades apreciáveis.

Objetivo: Desenvolvimento de lipossomos direcionáveis a células cancerosas por ação de ligantes específicos, como anticorpos gerando imunolipossomos.

Metodologia: Os imunolipossomos foram caracterizados pela adição de anticorpos covalentemente associados em seu exterior para receptores de tumores, por meio da ligação de tiolação. Os anticorpos policlonais foram obtidos da imunização de camundongos C57BL/6 contra tumores de origem humana em célula A549. Determinamos a toxicidade das partículas por meio de ensaios de viabilidade celular, pelo método XTT. Ainda, testamos a eficiência das partículas em experimentos in vivo, que foram aprovados de acordo com o registro CEUA pag.70/2017.

Resultados: Os ensaios de viabilidade celular demonstraram que os imunolipossomos diminuíram o IC 50 da cisplatina livre de 2,9 $\mu \mathrm{M}$ para 2,315 $\mu \mathrm{M}$. Essa eficiência seletiva in vitro corroborou para que seu uso in vivo fosse ainda mais eficiente, uma vez que in vivo a biodistribuição tende a se tornar mais vantajosa quando guiada. Com base nos resultados in vivo, obtivemos uma diminuição da massa tumoral em $25,1 \%$ nos animais tratados com os imunolipossomos em comparação ao tratamento padrão. Esse efeito de decrescimento tumoral foi obtidos mesmo reduzindo a quantidade de fármaco, no caso dos imunolipossomos com dose de $5 \mathrm{mg} / \mathrm{kg}$ enquanto que a dose convencional do tratamento com cisplatina é de 10 $\mathrm{mg} / \mathrm{kg}$, demonstrando então o potencial desse sistema.

Conclusão: Com tudo, obtivemos a caracterização e determinação do potencial dos lipossomos na entrega de drogas contra tumores promovendo o desenvolvimento de sistemas direcionáveis com amplos usos e aplicações imuno-farmacológicas.

Descritores: nanopartículas; imunolipossomos; tumores; nanomedicina; 


\section{DESENVOLVIMENTO DE IMUNOLIPOSSOMOS PARA O TRATAMENTO DE TUMORES}

\section{Introdução}

As nano partículas, em especial os lipossomos, possuem um grande potencial para o tratamento de diversas doenças, sobretudo para o câncer ${ }^{1,2}$. Atualmente, as pesquisas concentram-se no aprimoramento do uso de lipossomos, uma vez que sua administração fornece diversas vantagens como a liberação controlada de fármacos, o aumento da sua biodistribuição no local alvo, o aprimoramento da farmacocinética e a diminuição dos efeitos colaterais e da toxicidade da droga ${ }^{1-4}$.

Diante disso, os lipossomos podem ser aplicados como vetores desde a entrega de agentes antitumorais até terapias gênicas, como também na entrega de conteúdos vacinais para células de papel imunológico $2-5,13$. Com o intuito de otimizar a entrega seletiva de fármacos em locais específicos são desenvolvidas diferentes estratégias de alvos, tais como o emprego de biomoléculas como peptídeos e anticorpos na superfície da partícula ${ }^{6,7,11}$. Vale frisar que os recentes estudos visam à combinação multifuncional de alvos na superfície do lipossomo ${ }^{8}$. Os avanços nesta área permitem o direcionamento altamente seletivo, especializado e versátil 8,9 .

Neste contexto, propomos o desenvolvimento de sistemas direcionáveis com amplos usos e aplicações imuno-farmacológicas. Sendo assim, nesse projeto, produziremos partículas não catiônicas com anticorpos covalentemente associado em seu exterior para receptores de tumores, a fim de que a partícula se ligue ao receptor, como também seja transportada até o local alvo, aumentando dessa forma sua biodisponibilidade no local.

\section{Objetivo}

Como objetivo central esse projeto tem como intenção ampliar a busca de agentes carreadores tal como lipossomos que possam entregar agentes terapêuticos, focando em 
agentes antitumorais usando nano estruturas direcionáveis a tecidos e células específicas por ação de ligantes específicos, como anticorpos gerando imunolipossomos.

\section{Metodologia}

Produção de lipossomos neutros a partir de DPPC(Dipalmitoylphosphatidylcholine) numa proporção molar de 4:1 de DPPC:Colesterol. As formulações produzidas foram analisadas em aparelho Zeta-Analyzer, fornecendo as medições do potencial de carga e tamanho das partículas, como também da polidispersidade. Os imunolipossomos foram caracterizados pela adição de anticorpos covalentemente associados em seu exterior para receptores de tumores, por meio da ligação de tiolação. Os anticorpos policlonais foram obtidos da imunização de camundongos C57BL/6 contra tumores de origem humana em célula A549 e confirmados pelas técnicas de ELISA e Binding. Determinamos também a toxicidade das partículas por meio de ensaios de viabilidade celular, pelo método XTT. Ainda, testamos a eficiência das partículas em experimentos in vivo, que foram aprovados de acordo com o registro CEUA pag.70/2017.

\section{Resultados}

As formulações produzidas revelaram potencial de carga neutro, tamanho de $100 \mathrm{~nm}$ e polidispersividade de 0,3. Os ensaios de viabilidade celular demonstraram que os imunolipossomos diminuíram o IC $\mathrm{I}_{50}$ da cisplatina livre de 2,9 $\mu \mathrm{M}$ para 2,315 $\mu \mathrm{M}$. Essa eficiência seletiva in vitro corroborou para que seu uso in vivo fosse ainda mais eficiente, uma vez que in vivo a biodistribuição tende a se tornar mais vantajosa quando guiada. Com base nos resultados in vivo, obtivemos uma diminuição da massa tumoral em $25,1 \%$ nos animais tratados com os imunolipossomos em comparação ao tratamento padrão. Esse efeito de decrescimento tumoral foi obtidos mesmo reduzindo a quantidade de fármaco, no caso dos imunolipossomos com dose de $5 \mathrm{mg} / \mathrm{kg}$ enquanto que a dose convencional do tratamento com cisplatina é de $10 \mathrm{mg} / \mathrm{kg}$, demonstrando então o potencial desse sistema.

\section{Conclusão}

Com tudo, obtivemos a caracterização e determinação do potencial dos lipossomos na entrega de drogas contra tumores promovendo o desenvolvimento de sistemas direcionáveis 
com amplos usos e aplicações imuno-farmacológicas. O presente trabalho teve o potencial de produzir os parâmetros técnicos necessários para definir seu uso em ambos modelos para carrear agentes antitumorais norteando extrapolações futuras para o uso em humanos.

\section{Referências}

(1) Eloy, Josimar O., et al. "Immunoliposomes: a review on functionalization strategies and targets for drug delivery." Colloids and Surfaces B: Biointerfaces (2017).

(2) Park, John W., Christopher C. Benz, and Francis J. Martin. "Future directions of liposome-and immunoliposome-based cancer therapeutics." Seminars in oncology. Vol. 31. WB Saunders, 2004.

(3) Samad, Abdus, Y. Sultana, and M. Aqil. "Liposomal drug delivery systems: an update review." Current drug delivery 4.4 (2007): 297-305.

(4) Haley, Barbara, and Eugene Frenkel. "Nanoparticles for drug delivery in cancer treatment." Urologic Oncology: Seminars and original investigations. Vol. 26. No. 1. Elsevier, 2008.

(5) Lian, Tianshun, and Rodney JY Ho. "Trends and developments in liposome drug delivery systems." Journal of pharmaceutical sciences 90.6 (2001): 667-680.

(6) Pandey, V., and M. S. Chandran. "Liposome drug delivery." World Journal of Pharmacy and Pharmaceutical Sciences (2014).

(7) Maurer, Norbert, David B. Fenske, and Pieter R. Cullis. "Developments in liposomal drug delivery systems." Expert opinion on biological therapy 1.6 (2001): 923-947.

(8) Deshpande, Pranali P., Swati Biswas, and Vladimir P. Torchilin. "Current trends in the use of liposomes for tumor targeting." Nanomedicine 8.9 (2013): 15091528.

(9) Sanna, Vanna, Nicolino Pala, and Mario Sechi. "Targeted therapy using nanotechnology: focus on cancer." International journal of nanomedicine 9 (2014): 467.

(10)Cheng, Christopher J., et al. "MicroRNA silencing for cancer therapy targeted to the tumour microenvironment." Nature 518.7537 (2015): 107. 
(11)Mattheolabakis, George, Basil Rigas, and Panayiotis P. Constantinides. "Nanodelivery strategies in cancer chemotherapy: biological rationale and pharmaceutical perspectives." Nanomedicine 7.10 (2012): 1577-1590.

(12)Liu, Haipeng, and Darrell J. Irvine. "Guiding principles in the design of molecular bioconjugates for vaccine applications." Bioconjugate chemistry 26.5 (2015): 791 801.

(13)McCullough, Kenneth C., et al. "Self-amplifying replicon RNA vaccine delivery to dendritic cells by synthetic nanoparticles." Vaccines 2.4 (2014): 735-754. 